\title{
The feasibility case for converting existing heavy metro systems to driverless operation
}

\author{
P. Thomas
}

Parsons Group International Ltd, London, UK

\begin{abstract}
Bill Gates once said that 'The first rule of any technology used in a business is that automation applied to an efficient operation will magnify the efficiency. The second is that automation applied to an inefficient operation will magnify the inefficiency.'

The concepts and principles of driverless metro systems are well established, especially when applied to Automated People Movers and new build Metro Systems. Driverless operation can deliver significant operational and service benefits over conventionally operated lines. With the establishment of Driverless systems and the underlying enabling technologies the business case for converting an existing metro system to driverless operation is becoming increasingly feasible. To this extent many existing metro operators are either considering, planning or implementing driverless operation.

When considering converting an existing metro operation from a conventionally staffed operation a number of factors need to be assessed by the operator to evaluate the feasibility of the endeavour. These include but are not limited to: the operational and service benefits required from the system; the safety risk and subsequent control measures; the public perception and acceptance of the system; systems integration and migration from the existing to new system.

This paper will assess the principle factors that need to be addressed in the feasibility case for conversion of a heavy metro system to driverless operation. This paper is not setting out to provide an economic evaluation of such a scheme. However it is suggesting that it is possible to construct a feasibility case to convert an existing heavy metro system to driverless operation by considering the issues discussed in this paper.

Keywords: driverless operation, systems integration, systems engineering, automation, train control systems.
\end{abstract}




\section{Limitations with conventionally operated automatic train operation}

Conventional operations constrain the service offered by a metro operator in a number of key areas. With conventional operation the service is normally tied to the crew roster which makes it difficult to change the service pattern to respond to events on the network such as special events, perturbation recovery and schedule reformation. With the staff tied to the cab they are effectively unable to perform any other functions other than operating the train. Successful realisation of the benefits that are enabled through driverless operation requires a change to the operation of the railway. The key constraints and operational changes through driverless operation are summarised in Table 1.

Table 1: $\quad$ Summary of constraints.

\begin{tabular}{|l|l|}
\hline Conventional Operation & Driverless Operation \\
\hline $\begin{array}{l}\text { Service requires a train driver located } \\
\text { within a cab }\end{array}$ & $\begin{array}{l}\text { Service capable of operating without } \\
\text { staff, use of staff for operational } \\
\text { benefit. }\end{array}$ \\
\hline $\begin{array}{l}\text { Drivers manage the Platform Train } \\
\text { Interface (PTI) and despatch trains }\end{array}$ & $\begin{array}{l}\text { Automatic management of PTI, door } \\
\text { control, platform dwell time and train } \\
\text { despatch. Optional manual override } \\
\text { of door control for failure / dwell } \\
\text { management }\end{array}$ \\
\hline $\begin{array}{l}\text { Drivers are able to carry out remedial } \\
\text { actions }\end{array}$ & $\begin{array}{l}\text { Remote diagnostic / reset facilities } \\
\text { from the Control Centre }\end{array}$ \\
\hline $\begin{array}{l}\text { Perturbation recovery constrained due } \\
\text { to crew plans linked to train schedule, } \\
\text { staff availability and existing } \\
\text { recovery point. }\end{array}$ & $\begin{array}{l}\text { Perturbation recovery improved } \\
\text { through operational flexibility via } \\
\text { automatic-turnaround facilities and } \\
\text { train service completely decoupled } \\
\text { from staff plan. }\end{array}$ \\
\hline $\begin{array}{l}\text { The need for the driver to be on the } \\
\text { trains as they come into and out of } \\
\text { service constrains the flexibility of } \\
\text { operating staff. }\end{array}$ & $\begin{array}{l}\text { Operational staff can join train } \\
\text { anywhere along the line and allows } \\
\text { for increased staff flexibility. }\end{array}$ \\
\hline
\end{tabular}

\section{Key safety concepts and safety risks}

The introduction of driverless operation clearly impacts the overall safety of the railway. In some areas this can be seen as an increase in safety through reduction in human error and in other areas it is a reduction in the control measures afforded by the driver in the cab. This change in the safety of the railway, and the necessary control measures needs to be assessed as part of the business case for the project. Of particular importance is the extent to which implementation of these controls to an existing railway impacts the effectiveness of these safety measures. 
The effectiveness of control measures and proven systems applied to comparable systems to control the identified driverless operations hazards need to be evaluated in accordance with a recognised risk assessment methodology such as that defined in EN 50126. Where appropriate, modified or new safety control measures need to be introduced to reduce the hazard to a tolerable level. This analysis results in an understanding of the 'delta' required to mitigate driverless operation hazards and materialise potential safety benefits over and above the current operational situation.

Using this approach a hazard log and risk ranking can be created for the driverless system. Table 2 illustrates the top three hazards arising from the evaluation of the safety risks of converting a conventionally operated metro system to driverless operation.

Table 2: $\quad$ Top hazards.

\begin{tabular}{|c|c|c|}
\hline Top Event & Hazard & Possible Mitigation Options \\
\hline \multirow{8}{*}{$\begin{array}{l}\text { Platform / } \\
\text { Train } \\
\text { Interface }\end{array}$} & \multirow[t]{4}{*}{ Person On track } & Platform Edge Doors \\
\hline & & Fall detection and prevention \\
\hline & & Minimise mid car gaps \\
\hline & & Passenger awareness \\
\hline & \multirow{4}{*}{$\begin{array}{l}\text { Passenger Dragged } \\
\text { by train }\end{array}$} & Platform Edge Doors \\
\hline & & Trapped passenger detection \\
\hline & & $\begin{array}{l}\text { Operational staff at high risk areas / } \\
\text { times }\end{array}$ \\
\hline & & Passenger awareness \\
\hline \multirow[t]{5}{*}{ Collision } & \multirow[t]{3}{*}{ Object on track } & Object prevention \\
\hline & & Object detection \\
\hline & & Object deflector on train \\
\hline & \multirow[t]{2}{*}{ Infrastructure failure } & Infrastructure failure detection \\
\hline & & Speed restriction \\
\hline \multirow{6}{*}{$\begin{array}{l}\text { Ventilation } \\
\text { in tunnel } \\
\text { sections }\end{array}$} & \multirow[t]{6}{*}{ Passengers trapped } & Maintain air quality \\
\hline & & $\begin{array}{l}\text { Train movement ability maintained or } \\
\text { restored }\end{array}$ \\
\hline & & Passenger communications \\
\hline & & Remote driving \\
\hline & & Bi-directional signalling \\
\hline & & Evacuation to place of safety \\
\hline
\end{tabular}

\subsection{Platform Train Interface (PTI)}

Control measures used to ensure the safety risks associated with the PTI operation is tolerable include (as appropriate): The use of Platform Edge Doors (PED) fitted to the platforms to prevent access to the track area. PEDs will also provide an improved safety benefit over and above that of conventional 
operation by eliminating falls into the track area. The use of a Platform Track Intrusion Detection System (PTIDS) which prevents a train from entering the platform upon detection of egress into the track area. The use of 'Smart' doors which provide improved detection and release of obstacles trapped between the closing edges of the train doors.

\subsection{Collision with objects}

Control measures used to ensure the safety risks associated with the collision hazard are tolerable include (as appropriate): Prevention of access to the track through the use of security fencing along the perimeter and over-bridges; the deployment of CCTV and / or other technologies at strategic locations (trespass hot spots). Use of 'Sweep' trains at the start of service, utilising additional vigilance to prove that the track is clear of obstruction. Obstacle deflection by the front of the train (such as 'cow catcher') to reduce the consequence of a collision with an object.

\subsection{Ventilation in tunnel sections}

Trapped passengers are generally defined as those in a train that has been stopped between platforms for more than 30 minutes. The passenger perception of a train stuck in a tunnel is worse than one stuck on the surface, furthermore with small bore tunnels with no side access, passenger panic and thermal affects rise with time, temperature and crowding. In driverless operation where a member of staff may not be on board the primary control measures are to maintain train movement, air quality and ensure good passenger communications. Passenger self detrainment through the end of the train is a last resort.

\section{Customer perception}

Customer research has found that Customer awareness of driverless systems tends to be minimal; some users of existing driverless and conventional Automatic Train Operation (ATO) systems are not aware that these trains are driven automatically. At first, most rejected the concept of Underground trains without drivers and said it was imperative for someone to be in charge of the train. Once customers are aware of existing systems many are persuaded that technology for driverless operation not only exists but is tried and tested. Most come to the conclusion that driverless operation will not be an issue, as long as safety worries are addressed. They also expect that such a development will be part of a larger modernisation programme, to include updated trains and stations, and in this context driverless operation becomes more acceptable.

Customers still, however, want a member of staff on trains, who ideally would be able to take over and drive in an emergency. Security is key, and the absence of the presence of staff is a real cause for concern. 


\section{Performance measurement and service benefits}

When considering the performance benefits that can be achieved through driverless operation the primary measures are the improvement to the journey time and the change to the availability of the railway. Service benefits will also be realised through an increased visibility of staff capable of providing other service enhancing duties. The impact of driverless operation in these areas is discussed below.

\subsection{Journey time}

The improvements to journey time needs to consider the time to complete the journey under perturbation-free conditions and the additions to journey time caused by variations arising from: train running times; staff absences and errors; and minor equipment failures.

The key elements of the journey time measures that are impacted by driverless operation are discussed below. These are also summarised in figure 1 for a typical heavy metro system compared with the implementation of conventional ATO.

\subsubsection{Dwell time management}

Driverless operation will impact dwell management through a reduction in human intervention in the decision process to dispatch the train from the platform. Automatic door opening and closing will eliminate some of these inefficiencies but may also result in longer dwell times than necessary (as there is no driver to observe completion of the alighting and boarding process.) More regular dwell times enabled through automatic management of the platform dwell will lead to less variation in train frequency and provide a more regular service.

\subsubsection{Automatic turn-around}

The ability to automatically reverse the service without the need for human intervention or 'stepping back' will improve the turn-around time and allow an increase in train frequency. This can permit an improved service to be delivered with fewer trains than conventional operations and may also avoid costly infrastructure works to increase capacity at turn back locations.

\subsubsection{Train capacity}

Additional space is enabled by removal of cabs and possibly by using longer trains as the front and rear can extend beyond the ends of the platforms.

\subsubsection{Decoupling train and staff schedules}

Delays due to staff absences and unplanned personal-needs relief can be eliminated through driverless operation. There is more flexibility to optimise timetables when not constrained by staff duty periods. Train schedules can be adapted dynamically in response to perturbations or special events without being constrained by the availability of staff to operate the trains. 


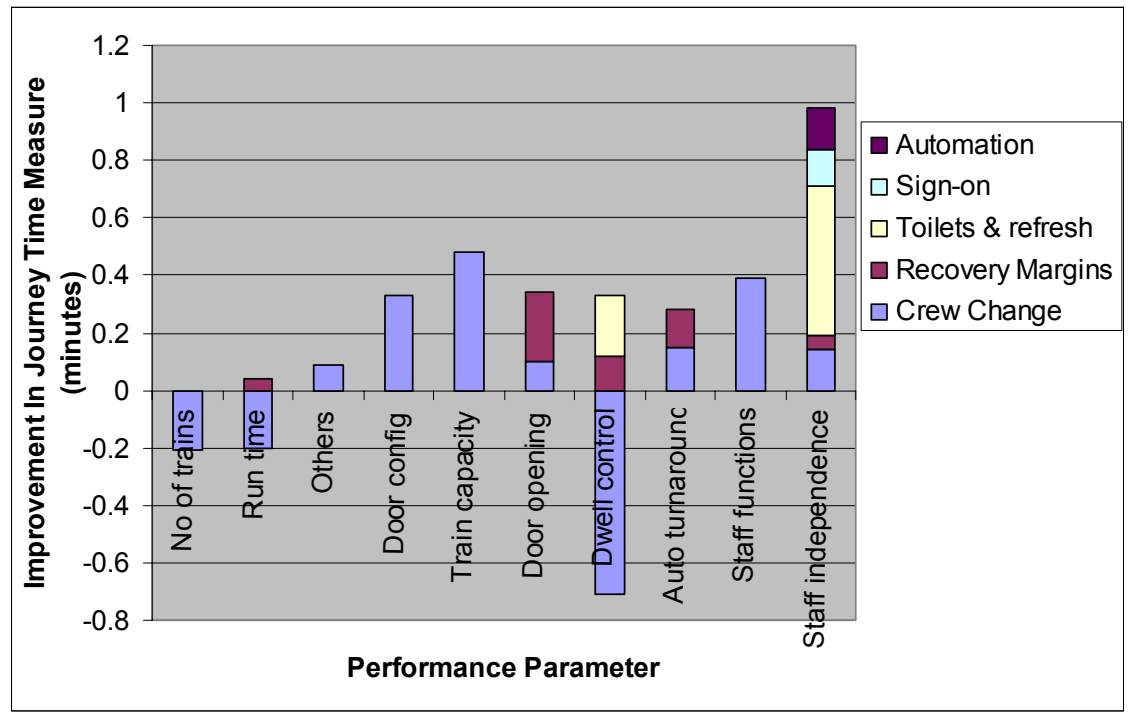

Figure 1: Improvement in Journey Time using conventional ATO as a baseline.

\subsection{Availability}

The availability of the railway will normally be expressed in terms of the loss of service through Service Affecting Incidents (SAI) and the time taken to recover from this Initial Delay to the service. The figure for SAI will normally be made up of asset failures and human error.

In this area driverless operation will also have a significant effect due to the introduction of new types of Service Affecting Incidents and modification of Initial Delays as there will not be a driver on-board to take remedial action. Remote fault diagnosis and rectification systems can be used to compensate for this effect. New degraded modes of operation will also be introduced by driverless operation which needs to be analysed. Some may adversely affect the availability in the absence of a driver but on the other hand, some train movements can be made more efficiently improving the overall availability. The availability of the railway will also be improved through a reduction in human error.

\subsection{Service benefits}

The improvements in service benefits to the metro system customer that can be enabled through driverless operation will generally be through the improved visibility of staff in customer facing roles. The evaluation of these benefits will tend to vary between metros but broadly speaking the presence of staff will improve the safety and security of the metro through a reduction in anti-social behaviour. It will also enhance revenue protection and enable an increase in 
accessibility to staff to provide passenger information especially to the infrequent users of the metro system. Driverless operation will change the working functions of operational staff, leading to more varied job roles and increased flexibility in staff deployment to fulfil these roles and benefits.

\subsection{Summary of benefits}

The benefits to the metro operator over and above conventional operation (including ATO) that may be realised through the implementation of driverless operation are briefly summarised in table 3 .

Table 3: $\quad$ Summary of benefits.

\begin{tabular}{|l|cl|}
\hline Benefit & Mechanism \\
\hline Improved journey & - Reduced service reversing times \\
time & - Consistent dwell times \\
& - Increase capacity \\
& - Staff independence from train operations \\
& & (e.g. staff absences, breaks) \\
\hline Increase operational & - Decouple crew plan from train schedule \\
flexibility & - Improve disruption recovery \\
& - Ease of introduction of new time tables \\
& - Multi skilled / flexible staff roles \\
\hline Reduced operating & - Deploy resources in accordance with \\
costs & - Reduce staff numbers \\
\hline $\begin{array}{l}\text { Increase safety and } \\
\text { security }\end{array}$ & - Reduction in safety duties of operations staff \\
\hline
\end{tabular}

\section{Systems engineering}

\subsection{System concepts}

Having established the key drivers and reasons to automate the system, the next step is to capture the key concepts that characterise the system. These will be used throughout the development to ensure compatibility and achievement of the overall project goals. These concepts embody the reasons for undertaking the project and form the basis of the subsequent systematic analysis of the requirements. This document, next to the business case itself, forms the singularly most important document in the feasibility case. In developing this document the aim is to capture the operational vision and key decisions which will form the basis of the new driverless system. Subsequent analysis through a well formed systems engineering process, will subsequently refine these 
concepts, but the important goal is to establish the fundamental changes and improvements that the enterprise wishes to make. The concepts of the new system and interactions of systems and people need to be assessed. The whole range of railway operational procedures and activities need not be covered in detail but merely in principle.

When considering the operating concepts it is important to bear in mind that conventional train operation is viewed as a system of operation consisting of people, processes and equipment, which operate within a particular environment to defined performance targets. The introduction of driverless operation seeks to enhance this capability with the introduction of new assets and systems. This increased capability enables the development of a system which allows for more effective operation of the railway as a whole. Driverless operation enables trains to be operated to the optimum levels of performance necessary to meet customer demand.

\subsection{Migration concepts}

When considering the feasibility of converting an existing operation attention needs to be given to the migration from the existing system to the new system. This also needs to include the operational organization. The operational concepts in each migration stage need to be understood and ultimately included within the system design. A number of options exist depending on the particular organisations starting point and experience with automation. The key migration principles need to consider the extent of the change being made and the experience of the operator to operate the railway in its new state (be it the final state or an interim migration stage). With a system operating as a 'line of sight', 'trip-cock' railway, the first migration stage would likely be to a 'Conventional' ATO railway, followed by migration to driverless operation with and then without an attendant on board, once the system reliability and operator confidence had been established. The level of automation that is achieved in each stage will depend on the satisfaction of both these factors, with the ability to return to a more restrictive operation should the need arise.

\subsection{Systems integration}

Clearly when automating an existing system, integration of the new system with existing assets needs to be understood. The various impacts that the proposed system will have, in the areas of operations, organisational changes, assets and advanced technologies, will need to be assessed. Trade-off studies should be used to assess the benefits of automation, for example in the areas of mixed mode operation a trade-off needs to be made between manual and automatic operation of the system. The arrangements for systems integration will need to be planned for all subsequent phases of the project. A key element of this at the outset is the development of the specifications that will be used to design the driverless system.

The requirements analysis process should completely specify the requirements of the driverless system that will satisfy the operational and 
business requirements, developed through a systematic engineering process as outlined in Figure 2. A first step in this process is the capture of the business requirements to establish the overall objectives for the automation of the system. This should involve sufficient stakeholder consultation to ensure that the objectives are correctly captured. An operational model should be developed in conjunction with the metro operator to characterise the required behaviour of the driverless network through the development of operational scenarios. It should identify the functions required to automate the train operation, through consideration of new, existing and special operational conditions such as mixed mode operations required by the metro operator. The system boundary should be used to define those systems that will be changed as a result of driverless operation. Safety, RAM and Performance models should be used to develop targets and requirements. These models and resulting analysis can then be used to refine the business requirements into a set of system requirements for the driverless system.

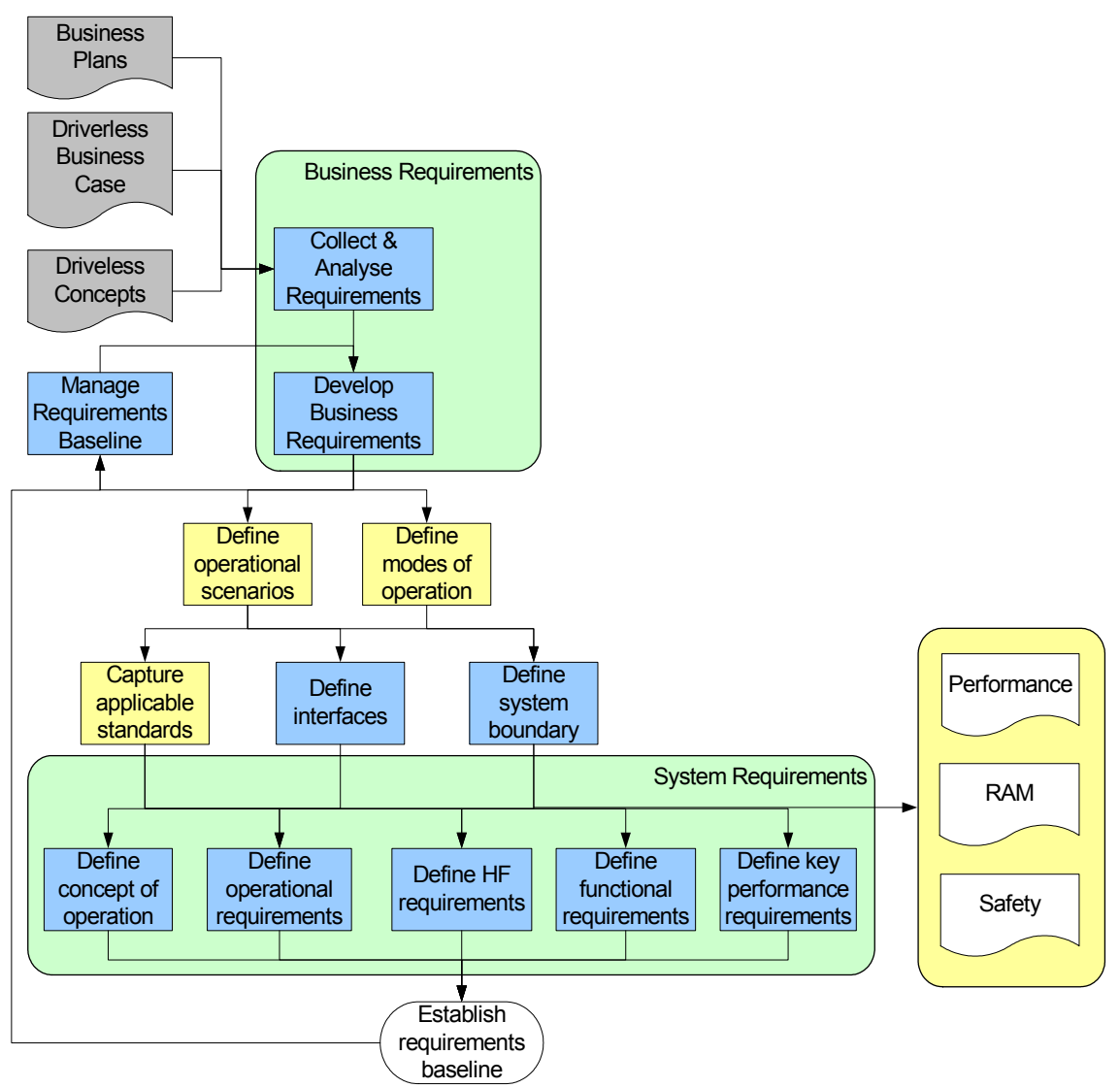

Figure 2: Requirements analysis process. 


\section{The business case}

Having established the system concepts, operational reasons, additional safety measures, expected benefits and disbenefits, the business case to automate the railway can be produced. This will need to provide an economic evaluation of the proposed system using the parameters relevant to the particular enterprise and will need to consider the operational model to be employed. Clearly the evaluation needs to assess the lifecycle costs of automation. The business case can be developed on a progressive basis throughout the feasibility phase of the project to establish an initial case and final case, as more detailed specifications and costs are developed.

\section{Conclusions}

The feasibility of automating an existing heavy metro system requires consideration of a number of complex factors. The most significant of these is the constraints with the existing system, the improvements required and the benefits that will be delivered through these changes. To realize these benefits a holistic approach to the feasibility, specification and implementation of the system needs to be undertaken and needs to include the operational organization. Driverless operation is an enabling technology for alternative models of train and station staff deployment requiring both technological and organisational changes. Through understanding of these factors the feasibility case can be assessed and significant improvements to the journey time, service benefits and operational costs can be achieved.

\section{Reference}

[1] Bill Gates, http://www.quotedb.com/quotes/3854. 